Jing Liu, Eckart Rühl*, Adam P. Hitchcock, David N. Mcllroy, John D. Bozek, Tolek Tyliszczak, Axel Knop-Gericke, Neil M. Boag, and Peter A. Dowben

\title{
Double Cation Formation from the Photo-Fragmentation of the closo-Carboranes
}

\begin{abstract}
Time-of-flight mass analysis with multi-stop coincidence detection has been used to study the multi-cation ionic fragmentation via fission of three isomeric carborane icosahedral cage compounds closo-1,2-orthocarborane, closo-1,7metacarborane, closo-1,12-paracarborane $\left(\mathrm{C}_{2} \mathrm{~B}_{10} \mathrm{H}_{12}\right)$ following inner-shell excitation at or above the $\mathrm{B} 1 \mathrm{~s}$ regime. Photoelectron-photoion-photoion coincidence (PEPIPICO) spectroscopy was used to study the dominant fission routes in the core level excitation regime. Series of ion pairs are identified, where asymmetric fission dominates, leading to ion pairs of different mass. The fragmentation yields and charge separation mass spectra of all three isomers are generally quite similar in that the ion pairs $\left(\mathrm{H}^{+}, \mathrm{Y}^{+}\right),\left(\mathrm{Y}^{+}, \mathrm{Y}_{11}^{+}\right)$, and $\left(\mathrm{Y}_{3}^{+}, \mathrm{Y}_{9}^{+}\right)$dominate, where $\mathrm{Y}^{+}$ denotes the mass region from $\mathrm{B}^{+}$to $\mathrm{CH}^{+}$. Slight differences are observed at the $\mathrm{B}$ 1s-threshold, where the $\mathrm{H}^{+}$and $\mathrm{BH}_{2}^{+} / \mathrm{CH}^{+}$ion pairs dominate for ortho- and metacarborane, while $\left(\mathrm{Y}^{+}, \mathrm{Y}_{11}^{+}\right)$ion pairs dominate the multi-photofragment ion yield of paracarborane. These similarities and distinct differences in charge separation are discussed by considering the energetics of these three major species of ion pairs, as well as charge distributions in closo-carboranes and charge distributions in the carborane cage. It is shown that product formation via charge separation is driven by electronic relaxation, so that the lowest energy products are not necessarily formed.
\end{abstract}

Keywords: Decomposition, Ionic Fragmentation, closo-Carboranes, Ionic Fragmentation Energetics, PEPIPICO.

\footnotetext{
*Corresponding Author: Eckart Rühl, Freie Universität Berlin, Physikalische Chemie und Theoretische Chemie, Institut für Chemie und Biochemie, Takustr. 3, D-14195 Berlin, Germany, Phone: +49 308385 2396, Fax: +49 308385 2717, e-mail: ruehl@zedat.fu-berlin.de Jing Liu, Peter A. Dowben: Department of Physics and Astronomy and the Nebraska Center for Materials and Nanoscience, Theodore Jorgensen Hall, 855 North 16th Street, University of Nebraska-Lincoln, Lincoln, NE 68588-0299, USA

Adam P. Hitchcock: Dept. of Chemistry \& Chemical Biology, McMaster University, Hamilton, Ontario L8S 4M1, Canada
} 
David N. Mcllroy: Department of Physics, Engineering and Physics Bldg., University of Idaho, Moscow, ID 83844-0903, USA

John D. Bozek: Stanford Linear Accelerator, LCLS Project, 2575 Sand Hill Road, Menlo Park, CA 94025, USA

Tolek Tyliszczak: Advanced Light Source, Lawrence-Berkeley Laboratory, Berkeley, CA 91420 , USA

Axel Knop-Gericke: Fritz-Haber-Institut der Max-Planck-Gesellschaft, Faradayweg 4-6, 14195 Berlin, Germany

Neil M. Boag: Materials and Physics Research Centre, Cockcroft Building, University of Salford, Salford M5 4WT, United Kingdom

Dedicated to: Professor Klaus Rademann on the occasion of his $60^{\text {th }}$ birthday

\section{Introduction}

Recently, there has been an effort to understand the ionic and photo fragmentation of the closo-carboranes [1-5]. This work has been fueled, in large measure, by a need to understand the growth and chemistry of the semiconducting boron carbides of approximate stoichiometry " $\mathrm{C}_{2} \mathrm{~B}_{10} \mathrm{H}_{x}$ " (where $x$ represents up to 40 at. \% fraction of hydrogen) [6], since the closo-1,2-orthocarborane is presently the favored source compound to grow semiconducting boron carbide thin films via plasma enhanced chemical vapor deposition (PECVD). At the B 1s and C 1s core level thresholds of boron and carbon, the energies are significantly larger than those applicable to most photo assisted [2] and PECVD [4-7] thin film material deposition techniques. The core excited and ionized states lead to extensive double ionization, and thus investigations of di-cation fragmentation via core level states are a complement to investigations of neutral and cation fragmentation. The three isomers of closo-carboranes have been studied in order to understand the mechanisms of the single ion fragmentation processes [1]. More recently, the dehydrogenation processes of semiconducting boron carbide and closo-carboranes were investigated by photoionization mass spectrometry studies [2].

There is sufficient photoionization cross-section $[1,8,9]$ and energy for cation pair production $[1,3]$ at the B 1s and C 1s core thresholds. Indeed at or above these thresholds, it has been noted that multiple fragment ion formation was not only possible, but likely, although not a majority fragmentation pathway $[1,3]$. There is already clear experimental evidence that the photo cation pair production of closo-1,2-orthocarborane does not lead to a statistical fragmentation of the icosahedral $\mathrm{C}_{2} \mathrm{~B}_{10} \mathrm{H}_{12}$ cage molecule and that some cation pairs are favored [3]. In our previous report [3], the photoelectron-photoion-photoion coincidence (PEPIPICO) technique was used to experimentally characterize cation pair formation pro- 
cesses in orthocarborane following high energy photoionization around the B 1s edge. Here we delineate some of the possible multiple cation formation processes that occur with the photofragmentation and photoionization of all three icosahedral closo-carboranes (illustrated in Figure 1) in the vicinity of the B 1s core threshold energy. The interpretation of the fragmentation mechanisms is aided by density functional theory calculations. Since dissociative double ionization is a major ionic decay route of core excited and ionized states [3, 10-20], it is important to be able to identify the signals corresponding to cation pair production. This can be done through an autocorrelation analysis of the ion signals measured in coincidence spectroscopies, such as photoion-photoion coincidence (PIPICO) mass spectra which mostly rely on time-of-flight mass spectrometry. This technique has been successfully used to investigate the ion formation in dissociative photoionization of some small molecules [18-20]. For large molecules with a rich mass spectrum and many dissociative channels, PIPICO spectra are very difficult to interpret on account of peak overlap due to the blended mass lines of same time-of-flight differences [12, 14, 21, 22].

Beyond PIPICO, the photoelectron-photoion-photoion coincidence (PEPIPICO) has been demonstrated to be a powerful technique in the study of three-body dissociations [3, 13, 21-26]. For larger molecular systems, it is better to use a multi-stop coincidence detection technique, where the individual ion flight times are identified rather than simply differences in flight time. We have used a multi-stop time-to-digital detection system to measure PEPIPICO spectra, also known as charge separation mass spectrometry (CSMS) [3, 13, 23-26] and have recently applied this approach to an investigation of the di-cation fragmentation of closo-1,2-orthocarborane [3]. This work extends that analysis and compares the results for closo-1,2-orthocarborane with those for closo-1,7-metacarborane and closo-1,12- paracarborane.

\section{Experimental methods}

All the isomers of $\mathrm{C}_{2} \mathrm{~B}_{10} \mathrm{H}_{12}$, i.e. orthocarborane (closo-1,2-dicarbadodecaborane or 1,2- $\mathrm{C}_{2} \mathrm{~B}_{10} \mathrm{H}_{12}$ ), metacarborane (closo-1,7-dicarbadodecaborane or $1,7-\mathrm{C}_{2} \mathrm{~B}_{10} \mathrm{H}_{12}$ ), paracarborane (closo-1,12-dicarbadodecaborane or 1,12- $\mathrm{C}_{2} \mathrm{~B}_{10} \mathrm{H}_{12}$ ), were purchased from either Katchem or Aldrich and resublimed prior to use, with purity in all cases confirmed by NMR spectroscopy, as described elsewhere [27].

As in prior measurements [3], the time-of-flight mass spectrometer consisted of a two stage acceleration region separated by grids, followed by a $30 \mathrm{~cm}$ drift tube. Wiley-McLaren space focusing conditions were used [14, 28]. A $-250 \mathrm{~V} / \mathrm{cm}$ extraction field was used for the cations. Under these conditions, splitting was 
generally not detected for any of the mass peaks, indicating there was negligible distortion of the yields due to loss of high kinetic energy ions. Note that the ${ }^{10} \mathrm{~B}$, ${ }^{11} \mathrm{~B}$ isotopes (natural abundance: $19.82 \%$ and $80.18 \%$, respectively [29]) and a variable number of hydrogen in the various fragments can lead to extensive peak overlap which tends to obscure or blur kinetic energy effects due to fission, except for processes leading to $\mathrm{H}^{+}$as one of the detected ions. The overall efficiency for ion detection is estimated to be about $15 \%$. The start of the flight time scale was the signal from an electron accelerated by a field of $+250 \mathrm{~V} / \mathrm{cm}$ for the experiments that were carried out at the Advanced Light Source, Berkeley, USA to a channelplate or a channeltron adjacent to the ionization region. This is similar to recent work on the orthocarborane [3].

In the photoelectron-photoion-photoion coincidence (PEPIPICO), three particles, the two positive ions and the electron, are detected. The detection of the electron provides a time zero from which the cation flight time to the detector of each of product ion was measured. PEPIPICO spectra were acquired at the Advanced Light Source using a custom built multi-stop time-to-digital converter with a time resolution of $12 \mathrm{~ns}$. Soft X-rays were obtained from undulator beamline 9.0.1 of the Advanced Light Source [30]. Similar results were obtained from the HE-TGM-2 beamline at BESSY I [31] (see also [3]). In order to avoid excessive accidental coincidences and to keep the overall event rates within the capacity of the processing system, rather narrow entrance and exit slits were used, typically $\sim 10 \mu \mathrm{m}$. The photon energy resolution was better than $0.1 \mathrm{eV}$ full width at half maximum (FWHM).

The individual ion flight times are proportional to the square root of ion mass. Where possible, we have plotted or indicated both flight times and estimated cation mass (in amu), as a matter of convenience. The peak shapes of PIPICO spectra were usually affected by several factors, such as apparatus discrimination, the kinetic energy release distribution, and the ion angular distribution [32, 33]. The general peak shapes for two body dissociations are rectangular, narrow single peak and double peak structure [34]. The peak shapes in PEPIPICO can also provide the information about the mechanism of dissociation processes $[3,35,36]$. The double cation fragmentation reaction obeys the law of conservation of momentum so that the two fragments have equal and opposite linear momenta. Thus, the peak projection in the $t_{1}-t_{2}$ plane normally has a slope of -1 . For three body dissociation, the neutral species could be ejected before charge separation (deferred charge separation) or after charge separation (secondary dissociation). The least likely process is that all fragments are generated at once (simultaneous Coulomb explosion). The slope of peak for deferred charge separation is -1 , while the absolute value of the secondary dissociation is the ratio of mass of the product to mass of its precursor. 


\section{Theoretical modeling}

Estimates of the energetics for the molecular di-cation decomposition processes were carried out by density functional theory (DFT) using the standard hybrid functional B3LYP, which has proven to be successful for other studies modeling the energetics of closo-carborane decomposition [1, 2]. The ground state and dissociation energies were calculated for possible dominating charge separation routes by performing B3LYP hybrid density functional theory (DFT) with the standard 6-31 $\mathrm{G}^{\star}$ basis set. The energies of three major ion pair species including $\left(\mathrm{H}^{+}\right.$, $\left.\mathrm{Y}^{+}\right),\left(\mathrm{BH}_{2}^{+} / \mathrm{CH}^{+}, \mathrm{Y}_{11}^{+}\right)$, and $\left(\mathrm{Y}_{3}^{+}, \mathrm{Y}_{9}^{+}\right)$(where $\mathrm{Y}^{+}$denotes the mass region from $\mathrm{B}^{+}$ to $\mathrm{CH}^{+}$- see below, vide infra, for more details of the this nomenclature) were constructed for the three isomers 1,2-, 1,7-, and 1,12- $\mathrm{C}_{2} \mathrm{~B}_{10} \mathrm{H}_{12}$ (ortho-, meta-, and paracarborane). All possible molecular structures of ion pairs with the same mass were considered in the modeling of each dissociation pathway. All appropriate symmetrically non-equivalent carbon and boron atom combinations from within the closo carborane were considered (i.e. re-arrangements were not included) and we report the fragmentation energies as those with the minimum energy cost.

\section{Di-cation fragmentation}

The photoion-photoion coincidence (PIPICO) mass spectra show the coincidence counts as a function of the difference in time of arrival of two ions, as exemplified in Figure 2 for metacarborane. In order to discuss these spectra compactly we have adopted a notation " $Y_{n}$ ", which refers to a cluster with n vertices with an unspecified mix of $\mathrm{BH}$ and $\mathrm{CH}$, such that the total number of vertices is $\mathrm{n}$ and the number of $\mathrm{CH}$ vertices cannot violate the overall stoichiometry of the parent molecule, as used in our previous work [3]. In mass spectra, the label $\mathrm{Y}^{+}$denotes the mass region from $\mathrm{B}^{+}$to $\mathrm{CH}^{+}$. As a result of stoichiometry of the molecules under study, the contribution of some number of $\mathrm{CH}$ components to any cation fragment is either 0 , 1 , or 2, for $n \geq 2$, and similar restrictions exist for $n=1$ and 2. Because of the $\approx 20: 80{ }^{10} \mathrm{~B}:{ }^{11} \mathrm{~B}$ natural abundance [29], each ion peak (except for the $\mathrm{Y}^{+}$ signal) is actually a family of peaks which cannot be resolved in the TOF spectra.

The most prominent peaks in the PIPICO spectra of metacarborane recorded at $192 \mathrm{eV}$ photon energy (Figure 2(a)) are associated with the following ion pairs $\left(\mathrm{H}^{+}, \mathrm{Y}^{+}\right),\left(\mathrm{Y}_{3}^{+}, \mathrm{Y}_{9}^{+}\right)$, and $\left(\mathrm{Y}^{+}, \mathrm{Y}_{11}^{+}\right)$. The differences of time of flight corresponding to these pairs are about at $1.16 \mu \mathrm{s}, 1.95 \mu \mathrm{s}$, and $3.75 \mu \mathrm{s}$, respectively. In Figure 2 (a) 

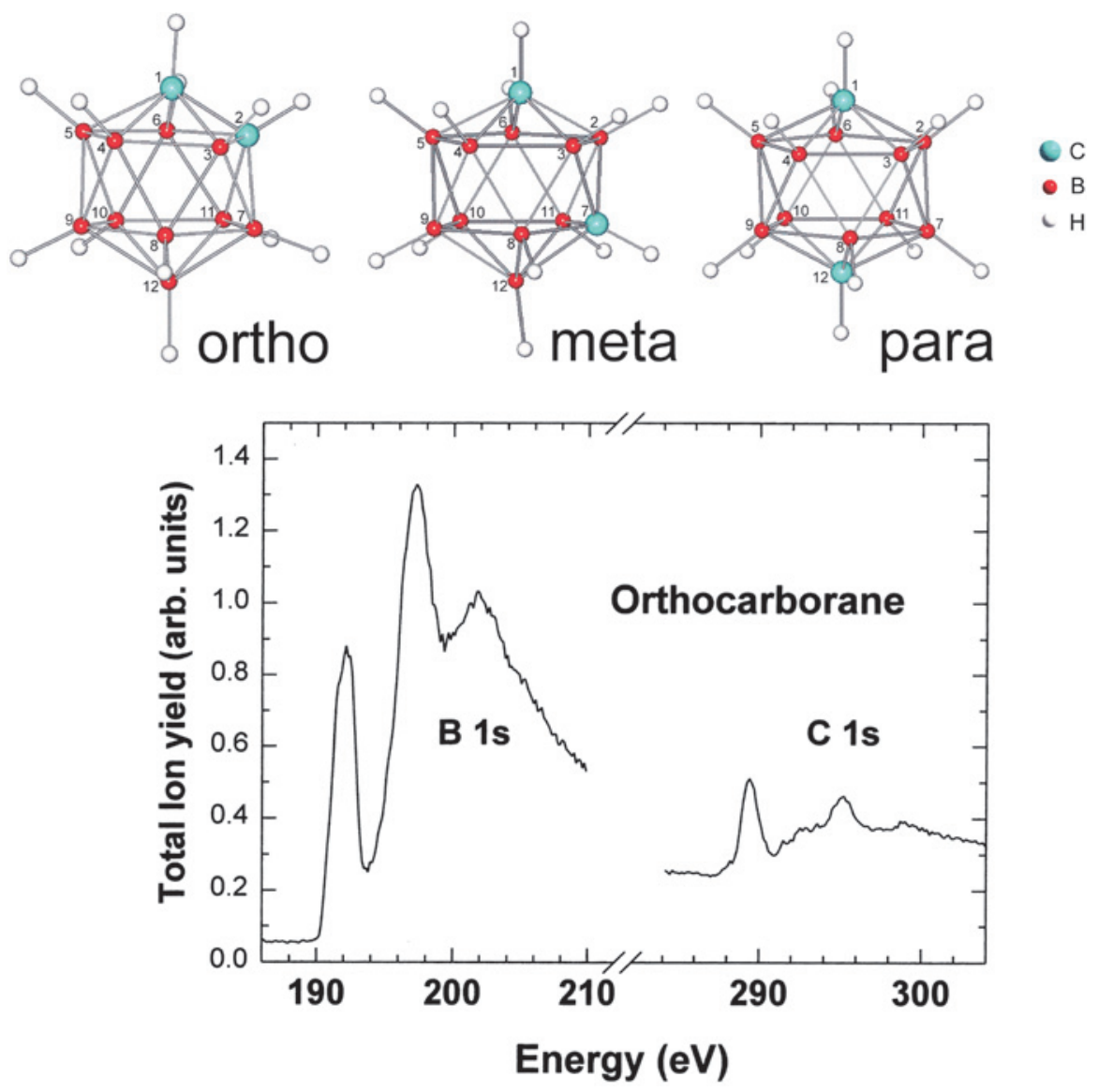

Figure 1: Schematic diagrams of the three isomers of closo- $\mathrm{C}_{2} \mathrm{~B}_{10} \mathrm{H}_{12}$, i.e. orthocarborane, metacarborane, paracarborane, with the total ion yield as a function of photon energy shown in the spectrum below for orthocarborane (closo-1,2-dicarbadodecaborane or 1,2- $\mathrm{C}_{2} \mathrm{~B}_{10} \mathrm{H}_{12}$ ) at the $\mathrm{B}$ 1s and $\mathrm{C}$ 1s thresholds. Adapted from [1] and [3], with permission. For the other isomer total ion yields see [9].

the shape of the peak for $\left(\mathrm{Y}_{3}^{+}, \mathrm{Y}_{9}^{+}\right)$fragment pair suggests a "narrow" single peak which indicates that most of the momentum is imparted perpendicular to spectrometer axis after dissociation. The peak corresponding to the $\left(\mathrm{Y}^{+}, \mathrm{Y}_{11}^{+}\right)$ionic fragments is slightly off rectangular, which suggests that there is likely little or no alignment after cation dissociation.

The triple coincidence PEPIPICO signals were recorded as a function of the flight times for each pair of ions. The ion masses were also calibrated from the time-of-flight mass spectra, as indicated elsewhere [1-3]. The PEPIPICO coinci- 


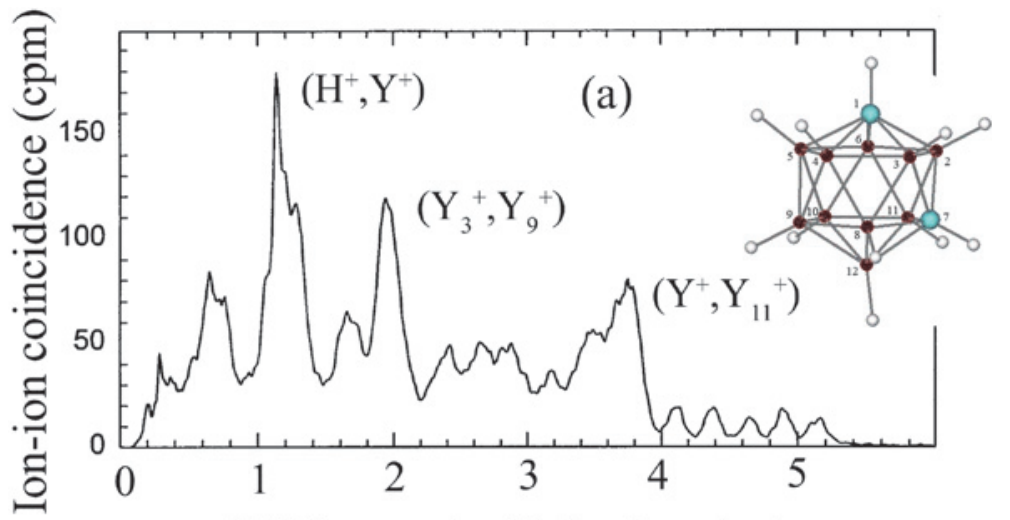

\section{Difference in flight time ( $\mu \mathrm{s})$}

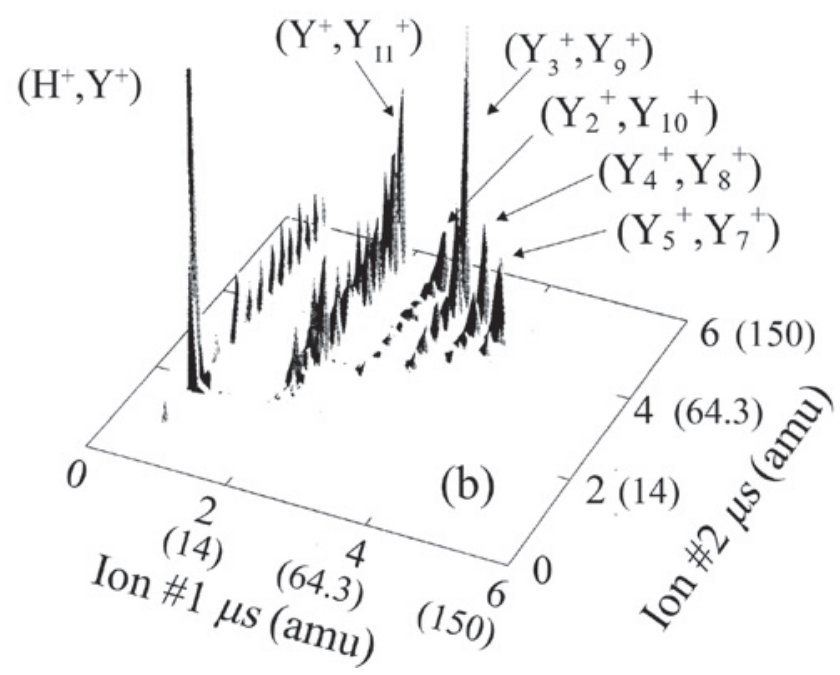

Figure 2: The (a) Photoion-photoion coincidence (PIPICO) spectrum (top) and the (b) photoelectron-photoion-photoion coincidence (PEPIPICO) spectrum (bottom) for metacarborane recorded at $192 \mathrm{eV}$ photon energy, at the peak of the lowest energy B 1s excitation (see Figure 1). The peaks corresponding to cluster fragments are denoted as $\mathrm{Y}_{n}^{+}$, where $\mathrm{Y}^{+}$denotes the mass region from $\mathrm{B}^{+}$to $\mathrm{CH}^{+}$.

dence signals for correlated cation pairs are plotted for metacarborane in Figure 2 (b) (taken at a photon energy of $192 \mathrm{eV}$ ), and for all three closo carborane isomers, in Figure 3 (taken at a photon energy of $202 \mathrm{eV}$ ). See Figure 1 for the energies correspond to spectral features in the total ion yield. The coincidence event information from the PEPIPICO spectra is rich. Three major groups of features are identified in Figure 2(b), for closo-1,7-carborane at a photon energy of $192 \mathrm{eV}$ the 


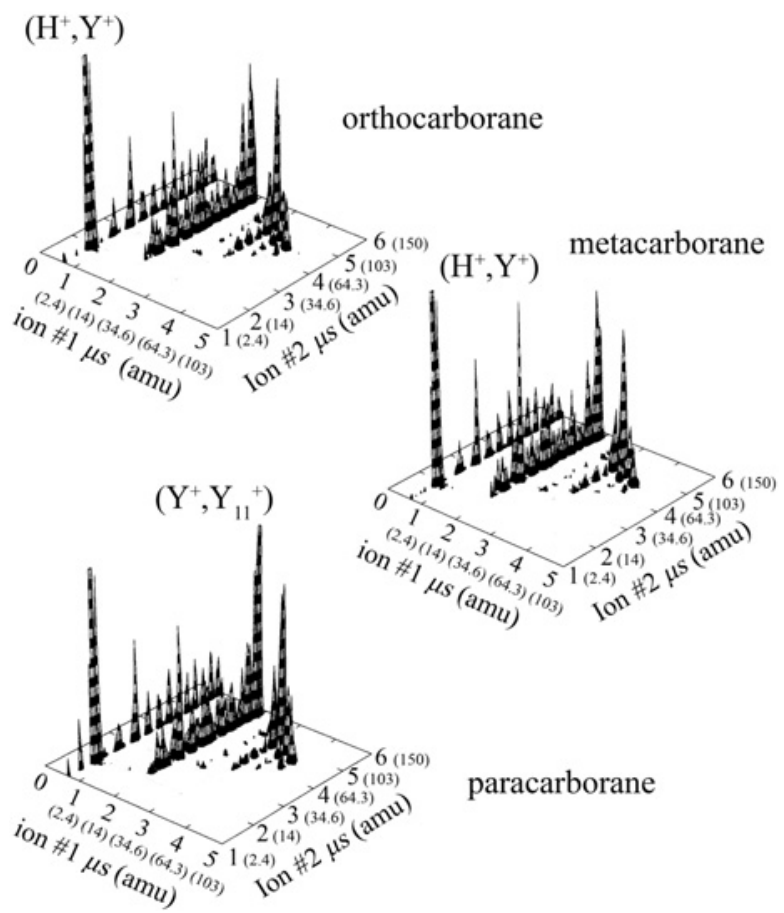

Figure 3: Photoelectron-photoion-photoion coincidence (PEPIPICO) spectra taken at a photon energy of $202 \mathrm{eV}$ for ortho-, meta- and paracarborane. The time of flight values have been converted to approximate mass values and denoted in brackets (amu). See Figure 2 for peak assignments.

first peak in the B 1s spectrum $[8,9]$. The signals of the $\left(\mathrm{H}^{+}, \mathrm{Y}^{+}\right)$ion pairs with the neutral $\mathrm{Y}_{11}$ fragment, the $\left(\mathrm{Y}^{+}, \mathrm{Y}_{11}^{+}\right)$ion pairs and the $\left(\mathrm{Y}_{3}^{+}, \mathrm{Y}_{9}^{+}\right)$ion pairs yields dominate the PEPIPICO spectra, which is consistent with the strongest PIPICO features.

The contour plots of the PEPIPICO peaks in the $t_{1}-t_{2}$ plane provide an excellent means for identifying the shape and intensities of the coincidence events. The contour plots of sections of the PEPIPICO spectrum for orthocarborane, at $220 \mathrm{eV}$ were reported previously [3]. They are similar to the data presented in this work. There are, however, distinct differences observed. Thus, in earlier work the light cation pairs $\left(\mathrm{H}^{+}, \mathrm{H}^{+}\right),\left(\mathrm{H}^{+}, \mathrm{Y}^{+}\right)$, and $\left(\mathrm{Y}^{+}, \mathrm{Y}^{+}\right)$dominated [3], whereas the cation pairs involving heavier fragments were significantly weaker in intensity. This differs from the present results and may essentially be due to differences in the excitation energy ( $220 \mathrm{eV}$ was used in Ref. [3] instead of $202 \mathrm{eV}$ in the current work), which influences the kinetic energy distribution of the electrons trigger- 
ing the detection in correlated ion pairs in PEPIPICO spectra. The ion yield ratios are also seen to vary with photon energy [1]. For the $\left(\mathrm{H}^{+}, \mathrm{Y}^{+}\right)$fission channels, the PEPIPICO spectra reported earlier [3] indicate that $\mathrm{H}^{+}$is predominantly correlated with ${ }^{11} \mathrm{~B}^{+}$and $\mathrm{CH}^{+}$as well as the unseen neutral fragment, which corresponds to $\mathrm{Y}_{11}$. The kinetic energy release corresponds to charge delocalization before fission.

In addition, there are numerous other asymmetric fission products indicating that the charges delocalize efficiently before fission and the kinetic energy release of these ion pairs can be explained by the geometry of the neutral molecule [3]. Specifically, it was previously observed [3] that the main signals in the $\left(\mathrm{Y}^{+}, \mathrm{Y}_{11}^{+}\right)$ pair yield correspond to the $\left({ }^{11} \mathrm{~B}^{+}, \mathrm{Y}_{11}^{+}\right)$and $\left(\mathrm{CH}^{+}, \mathrm{Y}_{11}^{+}\right)$ion pairs, where the $\left({ }^{11} \mathrm{~B}^{+}\right.$, $\left.\mathrm{Y}_{11}^{+}\right)$pair is dominant and $\mathrm{Y}_{11}^{+}$corresponds to $m / z=124$. The slope of the $\left(\mathrm{B}^{+}\right.$, $\mathrm{Y}_{11}^{+}$) signal is -10.05 , which is typical for two body fission or deferred charge separation. Overall, asymmetric dissociation dominates the dissociation processes of 1,2-orthocarborane [3]. This is typical for most fission processes of cluster dications [15].

The photoelectron-photoion-photoion coincidence time-of-flight (PEPIPICO TOF) mass spectra of the three carboranes, excited by $202 \mathrm{eV}$ photons, are compared in Figure 3. This energy corresponds to a B 1s $\rightarrow \sigma^{*}$ transition [9] (third peak in the B 1s spectrum, as illustrated in Figure 1). Clearly the fragmentation yields and charge separation mass spectra at a photon energy of $202 \mathrm{eV}$ for all three isomers are generally quite similar in the overall shape of PEPIPICO spectra, in which the following ion pairs dominate: $\left(\mathrm{H}^{+}, \mathrm{Y}^{+}\right),\left(\mathrm{Y}^{+}, \mathrm{Y}_{11}^{+}\right)$, and $\left(\mathrm{Y}_{3}^{+}, \mathrm{Y}_{9}^{+}\right)$. The coincidence signal strength increases as the incident photon energy is increased from 192 to $202 \mathrm{eV}$. This is well-known and is due to changes in ionization yield, i.e. the number of charges created per absorbed photon [12]. The $\left(\mathrm{H}^{+}, \mathrm{Y}^{+}\right)$ion pairs dominate the multi-photofragment ion yield of ortho- and metacarborane at the $\mathrm{B}$ 1s threshold, while the $\left(\mathrm{Y}_{1}^{+}, \mathrm{Y}_{11}^{+}\right)$ion pairs have almost same intensity as the $\left(\mathrm{H}^{+}\right.$, $\mathrm{Y}^{+}$) ion pairs for paracarborane at the B 1s threshold (Figure 3). These slight differences in fission channel intensities are likely due to the local surroundings of three isomers, as will be discussed in the following Section.

\section{Discussion}

To further examine the favorable pathways of double ionization of the three isomers of closo-carboranes, the dissociation energies of the three major ion pairs species observed in both the PIPICO and PEPIPICO mass spectra were calculated to seek the dominant charge separation routes by consideration of Reac- 


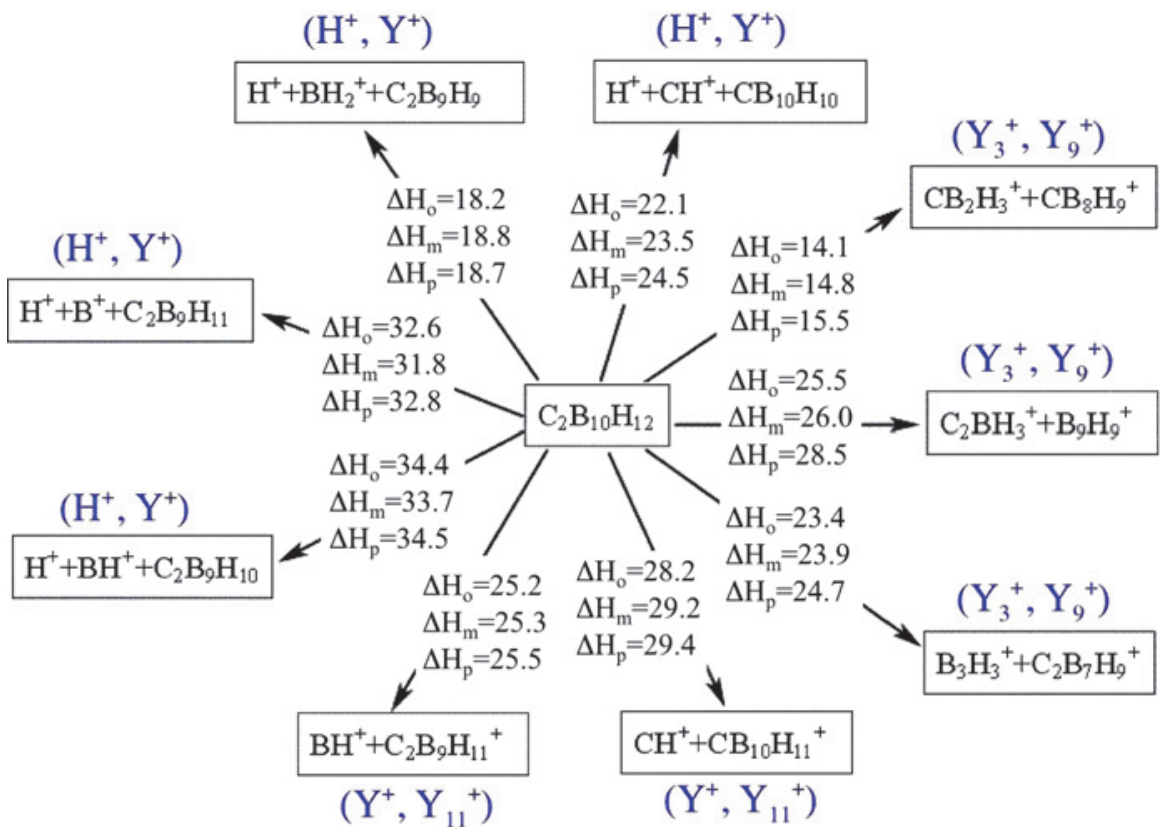

Figure 4: Energetics of ortho-, meta-, and paracarborane double ion fragmentation for experimentally observed ion pairs $\left(\mathrm{H}^{+}, \mathrm{Y}^{+}\right),\left(\mathrm{Y}^{+}, \mathrm{Y}_{11}^{+}\right)$, and $\left(\mathrm{Y}_{3}^{+}, \mathrm{Y}_{9}^{+}\right)$. All energies were calculated using density functional theory and are given in units of $\mathrm{eV} /$ molecule.

tions (1), (2), and (3):

$$
\begin{aligned}
& \mathrm{C}_{2} \mathrm{~B}_{10} \mathrm{H}_{12}+h v \rightarrow \mathrm{H}^{+}+\mathrm{Y}^{+}+\mathrm{Y}_{11}+2 e^{-} \\
& \mathrm{C}_{2} \mathrm{~B}_{10} \mathrm{H}_{12}+h v \rightarrow \mathrm{Y}^{+}+\mathrm{Y}_{11}^{+}+2 e^{-} \\
& \mathrm{C}_{2} \mathrm{~B}_{10} \mathrm{H}_{12}+h v \rightarrow \mathrm{Y}_{3}^{+}+\mathrm{Y}_{9}^{+}+2 e^{-}
\end{aligned}
$$

The corresponding minimum values for the dissociation energies associated with each fragmentation reaction are shown in Figure 4.

Due to the limited resolution of our time-of-flight mass spectrometers and the substantial kinetic energy release due to fission, ions with the same or similar mass to charge ratio cannot be distinguished in the TOF mass spectra. In three body fission processes (1), we examined the energy cost separately for dissociative pathways including $\mathrm{H}^{+}, \mathrm{Y}^{+}$as $\mathrm{B}^{+}, \mathrm{BH}^{+}, \mathrm{CH}^{+}$and $\mathrm{BH}_{2}^{+}$, and corresponding neutral fragments. The boron atom in all the calculations was assumed to be ${ }^{11} \mathrm{~B}$. Even with consideration of all the possible molecular structures of ion pairs with same mass in modeling for each dissociation pathway related to the Reactions (1)-(3), the lower energy dissociation processes are not always favored. Comparing the 
calculated minimum energy cost for the fission reaction for all three isomers, it appears energetically that $\left(\mathrm{H}^{+}, \mathrm{Y}^{+}\right)$pairs are generally most favorable experimentally (Figure 3) and yet the $\left(\mathrm{Y}_{3}^{+}, \mathrm{Y}_{9}^{+}\right)$pair production of $\left(\mathrm{CB}_{2} \mathrm{H}_{3}^{+}, \mathrm{CB}_{8} \mathrm{H}_{9}^{+}\right)$is favored energetically according to the calculations.

In Reaction (2), resulting in production of the $\left(\mathrm{Y}^{+}, \mathrm{Y}_{11}^{+}\right)$ion pairs, dissociation energies corresponding to formation of $\left(\mathrm{BH}^{+}, \mathrm{C}_{2} \mathrm{~B}_{9} \mathrm{H}_{11}^{+}\right)$and $\left(\mathrm{CH}^{+}, \mathrm{CB}_{10} \mathrm{H}_{11}^{+}\right)$ were compared. Energetically, $\mathrm{BH}^{+}$is preferred over $\mathrm{CH}^{+}$formation. However, in PEPIPICO spectra $\mathrm{B}^{+}$and $\mathrm{CH}^{+}$are correlated with $m / z=124$, whereas $\mathrm{BH}^{+}$is barely observed in this ion-pair channel [3]. For the $\left(\mathrm{Y}_{3}^{+}, \mathrm{Y}_{9}^{+}\right)$pairs, the $\left(\mathrm{CB}_{2} \mathrm{H}_{3}^{+}\right.$, $\left.\mathrm{B}_{8} \mathrm{H}_{9}^{+}\right)$pair combination is more favored than $\left(\mathrm{C}_{2} \mathrm{BH}_{3}^{+}, \mathrm{B}_{3} \mathrm{H}_{3}^{+}\right)$as a choice for the lighter fragment. Energetic arguments indicate that the $\mathrm{Y}_{3}^{+}$ion that is removed from the parent molecule comes preferentially from a corresponding face or linear chain on the pseudo icosahedral cage rather than separate sites on the cage. For example, for $\mathrm{B}_{3} \mathrm{H}_{3}^{+}$ions the energy cost corresponding to removing a face or chain from the icosahedral cage could be as much as 3.6, 3.3, and $0.8 \mathrm{eV}$ less than separate sites for orthocarborane, metacarborane and paracarborane, respectively.

It is likely that the local dipoles of the di-cation parent molecules play a role in the experimentally favored dissociation processes. In comparing the calculated di-cation fragmentation dissociation energies to the experimentally observed major ion pair pathways, the significant differences observed for paracarborane (Figure 3) relative to metacarborane or orthocarborane are not reflected in the calculated energetics (Figure 4). This suggests that for paracarborane, the difference in the atomic pair local dipole attraction may play a role, particularly if $\mathrm{CH}^{+}$is a favored fragment, as suggested by prior work [3]. Although the energy cost pathways among the two possible fission pathways of $\left(\mathrm{Y}^{+}, \mathrm{Y}_{11}^{+}\right)$suggests that $\mathrm{BH}^{+}$may be more preferred (Figure 4), even if for orthocarborane $\left(\mathrm{CH}^{+}, \mathrm{Y}_{11}^{+}\right)$is experimentally found to be the favored ion pair combination [3]. This may be the origin of the increase in the relative intensity of the di-cation coincidence feature corresponding to $\left(\mathrm{Y}^{+}, \mathrm{Y}_{11}^{+}\right)$seen in paracarborane (Figure 3) compared to the $\left(\mathrm{H}^{+}, \mathrm{Y}^{+}\right)$ di-cation fragment production. This seems to occur in spite of the reduced energy cost of the $\left(\mathrm{H}^{+}, \mathrm{Y}^{+}\right)$di-cation fragment production compared to $\left(\mathrm{Y}^{+}, \mathrm{Y}_{11}^{+}\right)$, even for paracarborane (Figure 4).

Table 1 presents the calculated dissociation energies for ion pairs involving $\mathrm{Y}_{2}^{+}$and $\mathrm{Y}_{3}^{+}$. The $\left(\mathrm{CB}_{2} \mathrm{H}_{3}^{+}, \mathrm{CB}_{8} \mathrm{H}_{10}^{+}\right)$ion pairs are most preferred on the basis of energetics. The energy cost is about $8.6 \mathrm{eV}$ to $10 \mathrm{eV}$ lower than the $\left(\mathrm{B}_{2} \mathrm{H}_{2}^{+}, \mathrm{C}_{2} \mathrm{~B}_{8} \mathrm{H}_{10}^{+}\right)$ ion pairs and $11.2 \mathrm{eV}$ to $12.9 \mathrm{eV}$ lower than the $\left(\mathrm{CBH}_{2}^{+}, \mathrm{CB}_{9} \mathrm{H}_{10}^{+}\right)$ion pairs. Energetically, $\mathrm{Y}_{3}^{+}$is more stable and favored in fission processes than $\mathrm{Y}_{2}^{+}$. This is in generally good agreement with the PIPICO and PEPIPICO observations. It is observed that the fission processes involving $\mathrm{Y}_{2}^{+}$are weak in PEPIPICO, which is due 
Table 1: Comparison of energies required to create ion pairs of $\left(\mathrm{Y}_{3}^{+}, \mathrm{Y}_{9}^{+}\right)$and $\left(\mathrm{Y}_{2}^{+}, \mathrm{Y}_{10}^{+}\right)$, where $\mathrm{Y}^{+}$ denotes the mass region from $\mathrm{B}^{+}$to $\mathrm{CH}^{+}$.

\begin{tabular}{lcccc}
\hline & $\begin{array}{c}\mathrm{B}_{3} \mathrm{H}_{3}^{+}+\mathrm{C}_{2} \mathrm{~B}_{7} \mathrm{H}_{9}^{+} \\
\left(\mathrm{Y}_{3}^{+}, \mathrm{Y}_{9}^{+}\right) \\
(\mathrm{eV})\end{array}$ & $\begin{array}{c}\mathrm{B}_{2} \mathrm{H}_{2}^{+}+\mathrm{C}_{2} \mathrm{~B}_{8} \mathrm{H}_{10}^{+} \\
\left(\mathrm{Y}_{2}^{+}, \mathrm{Y}_{10}^{+}\right)\end{array}$ & $\begin{array}{c}\mathrm{CB}_{2} \mathrm{H}_{3}^{+}+\mathrm{CB}_{8} \mathrm{H}_{9}^{+} \\
\left(\mathrm{Y}_{3}^{+}, \mathrm{Y}_{9}^{+}\right) \\
(\mathrm{eV})\end{array}$ & $\begin{array}{c}\mathrm{CBH}_{2}^{+}+\mathrm{CB}_{9} \mathrm{H}_{10}^{+} \\
\left(\mathrm{Y}_{2}^{+}, \mathrm{Y}_{10}^{+}\right) \\
(\mathrm{eV})\end{array}$ \\
\hline Orthocarborane & 23.359 & 24.159 & 14.126 & 25.607 \\
Metacarborane & 23.922 & 24.324 & 14.826 & 26.308 \\
Paracarborane & 24.696 & 24.045 & 15.479 & 28.347 \\
\hline
\end{tabular}

to the instability of $\mathrm{Y}_{2}^{+}$. On inspection of the detailed fragment intensities (Figures 2 and 3), we see more evidence that energetics is not the sole guide to favored di-cation production. It is clear that charge density distributions must also be considered. Dipolar character or strong cation character localized on some bonds will favor those moieties for cation formation in molecular dissociation events. The deviations in cation fragmentation expected from the energetics (Figure 4) are much better understood when one takes note of the anisotropic charge distributions visualized in Figure 5, and summarized in Table 2. For the corresponding $\left(\mathrm{Y}^{+}, \mathrm{Y}_{11}^{+}\right)$ di-cation pair production, $\left(\mathrm{BH}^{+}, \mathrm{Y}_{11}^{+}\right)$should be favored over $\left(\mathrm{CH}^{+}, \mathrm{Y}_{11}^{+}\right)$according to energetic considerations. However, even for orthocarborane, $\left(\mathrm{CH}^{+}, \mathrm{Y}_{11}^{+}\right)$is favored [3], indicating that the lowest energy routes do not occur with the highest abundance in the PEPIPICO spectra.

The calculated Mulliken charge populations (Table 2) indicate that, for the dication, the strongest local dipole is at the $\mathrm{C}-\mathrm{H}$ bond for each of the three isomers. In Reaction (2), this provides one reason for $\left(\mathrm{CH}^{+}, \mathrm{Y}_{11}^{+}\right)$being favored over $\left(\mathrm{BH}^{+}\right.$, $\left.\mathrm{Y}_{11}^{+}\right)$in the $\left(\mathrm{Y}^{+}, \mathrm{Y}_{11}^{+}\right)$di-cation pair production, as was experimentally observed for orthocarborane [3]. The fact that the B-H bond is not usually a strong dipole in the di-cation tends to explain why $\mathrm{B}^{+}$separation from $\mathrm{H}^{+}$is far more commonly observed than $\mathrm{C}^{+}$separation from $\mathrm{H}^{+}$in the di-cation fragmentation route (1) [3].

The fact that paracarborane favors the di-cation pair fragmentation $\left(\mathrm{Y}^{+}, \mathrm{Y}_{11}^{+}\right)$ (Reaction (2)) far more than metacarborane and orthocarborane (as seen in Figure 3), is not explained as easily by the local charge populations or the ground state energetics. It is rather assumed that in a sequence of core level excitation and relaxation preceding fragmentation via fission has to be considered along with the local surroundings of the core-excited sites. This implies that in the present study the boron sites are exclusively initially excited. However, the electronic structure of the B 1s-excited carboranes is known to be quite delocalized [9]. Subsequent Auger relaxation will create the di-cations or even triply charged cages, where the sinks for positive charges can be identified from Figure 5. The energy remaining 


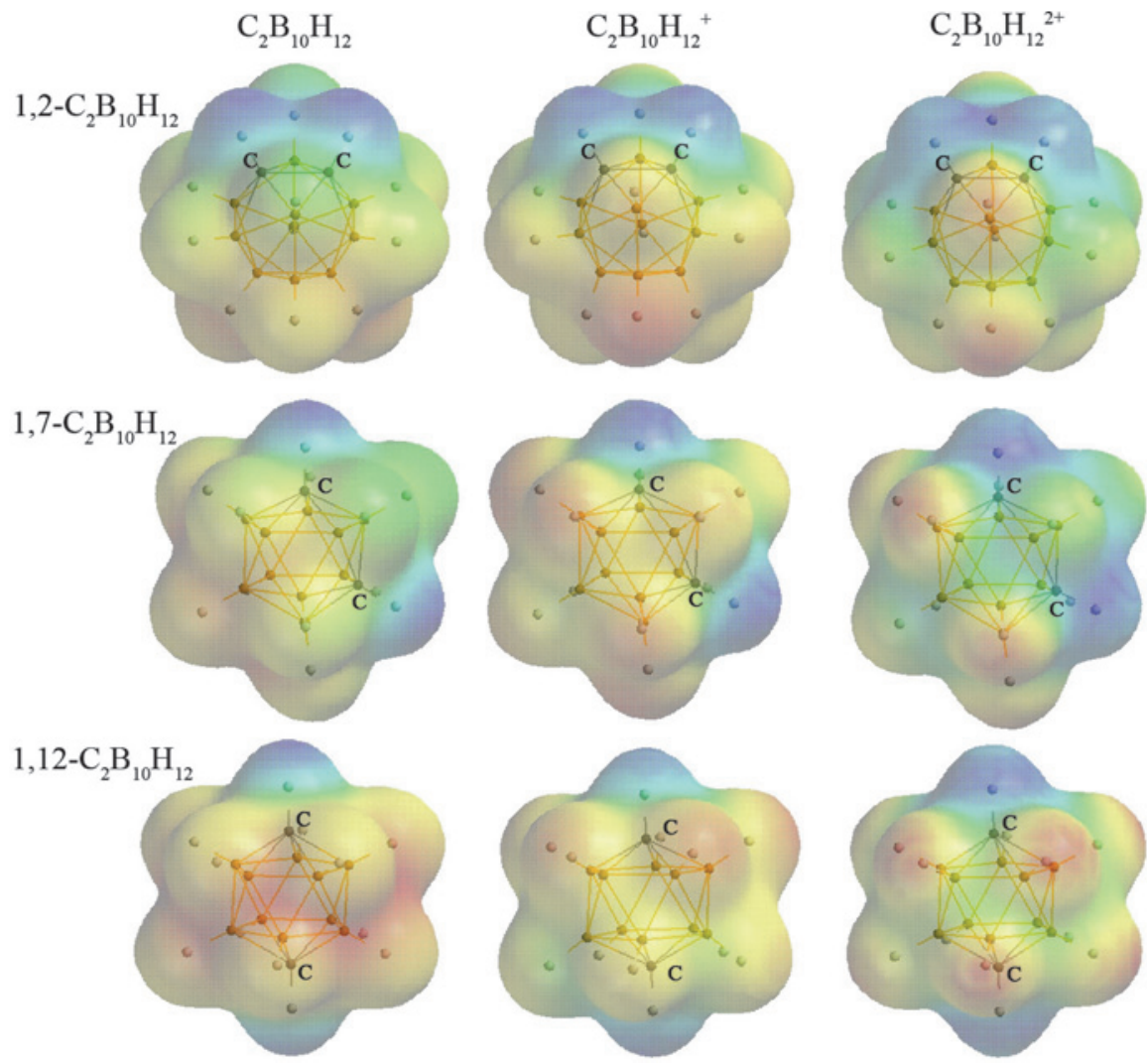

Figure 5: Changes in the relative surface charge densities of the three closo-dicarbadocedaborane isomers, from neutral (left) to cation (center) to di-cation (right). Blue color indicates relatively more positive charge, whereas red color indicates negative charge.

Table 2: Selected atomic charges (|e|) of $\mathrm{H}$ and B/C on selected positions for closocarborane di-cations, calculated by the Mulliken method.

\begin{tabular}{llrrrrrr}
\hline $\begin{array}{l}\text { Main Group Atom } \\
\text { Position }\end{array}$ & & 1 & 2 & 4 & 7 & 10 & 12 \\
\hline $1,2-\mathrm{C}_{2} \mathrm{~B}_{10} \mathrm{H}_{12}^{2+}$ & $\mathrm{H}$ & 0.349 & 0.3349 & 0.256 & 0.256 & 0.182 & 0.209 \\
& $\mathrm{~B} / \mathrm{C}$ & -0.373 & -0.373 & -0.067 & 0.067 & 0.033 & -0.014 \\
& $\mathrm{H}$ & 0.339 & 0.256 & 0.204 & 0.339 & 0.247 & 0.196 \\
$1,7-\mathrm{C}_{2} \mathrm{~B}_{10} \mathrm{H}_{12}^{2+}$ & $\mathrm{B} / \mathrm{C}$ & -0.419 & -0.018 & 0.020 & -0.419 & -0.067 & 0.020 \\
& $\mathrm{H}$ & 0.335 & 0.253 & 0.253 & 0.253 & 0.253 & 0.335 \\
$1,12-\mathrm{C}_{2} \mathrm{~B}_{10} \mathrm{H}_{12}^{2+}$ & $\mathrm{B} / \mathrm{C}$ & -0.383 & -0.043 & -0.043 & -0.043 & -0.043 & -0.383 \\
\hline
\end{tabular}


in the di-cation after electronic relaxation is not exactly known since there have been no resonance Auger spectra published to the best of our knowledge. However, one can expect that the energy that is available in the di-cations is well above the energies calculated in Figure 4. This can be estimated by the 'rule of thumb' for direct double ionization [37], indicating that the threshold for direct double ionization is about 2.8 times the first ionization energy. If one uses the values of the first ionization energies of the compounds under study [2], one derives a double ionization energy of about $28 \mathrm{eV}$. Most of the values shown in Figure 4 are below this threshold value. Furthermore, Auger relaxation is expected to leave substantially more energy in the di-cations, so that all calculated routes can be accessed.

The present results indicate that charge localization at the carbon sites has a crucial role, which is consistent with earlier work [3]. There it was shown that for the $\left(\mathrm{Y}^{+}, \mathrm{Y}_{11}^{+}\right)$channel the $\mathrm{CH}^{+}$contribution is intense and only minor intensity was observed for $\mathrm{BH}^{+}$. The occurrence of an intense $\mathrm{B}^{+}$signal may be an indication for secondary stabilization of an intermediate $\mathrm{BH}^{+}$. Differences between the isomers under study are found in the local surroundings of the absorbing boron sites. In the case of orthocarborane there are four sites that are not directly bound to carbon, in the case of m-carborane these are only two such boron sites, whereas for paracarborane all boron sites are directly bound to carbon. This might be a hint to a plausible rationalization for the slightly different fission patterns in the different isomers, since charge delocalization will certainly precede prior to fission, yielding the distinct differences in intense ion pair channels via fission.

\section{Conclusion}

In this study of the coincidence time-of-flight (PEPIPICO TOF) mass spectra of three closo-carborane isomers taken using photo-excitations in vicinity of the B $1 \mathrm{~s}$ core threshold, we see many similarities between the three isomers. Fragmentation yields and charge separation mass spectra of all three isomers are generally quite similar in that the ion pairs $\left(\mathrm{H}^{+}, \mathrm{Y}^{+}\right),\left(\mathrm{Y}^{+}, \mathrm{Y}_{11}^{+}\right)$, and $\left(\mathrm{Y}_{3}^{+}, \mathrm{Y}_{9}^{+}\right)$dominate, where $\mathrm{Y}^{+}$denotes the mass region from $\mathrm{B}^{+}$to $\mathrm{CH}^{+}$. The strong dominance of selected cation pairs indicates that the di-cation fragmentation is not a statistical process, i.e. it is not solely governed by the fragmentation energetics. Distinct differences in intensity of the main fission channels between the isomers are observed, which are rationalized in terms of changes in local structure. With the di-cation in the vicinity of the B 1s core threshold, we find that the fragmentation energetics are not an infallible guide to the observed fragmentation. This is quite different 
from the more simple cation fragmentation [1] and the loss of $\mathrm{H}_{2}$ from the parent cation [2], where the energetics are a reliable indicator of the likely fragmentation pathways.

Acknowledgement: Die Autoren möchten die Atmosphäre und die engagierten Diskussionen in den Kellerbüros und Laboren der Takustraße 3 würdigen. Spezieller Dank gebührt Klaus Rademann für seine grundlegende Rolle in der Clusterchemie, fortführt von einigen Autoren dieses Artikels (P. A. D. + E. R). This work was supported by the Defense Threat Reduction Agency (Grant No. HDTRA109-1-0060), the Deutsche Forschungsgemeinschaft through grant RU 420/8-1, the Fonds der Chemischen Industrie and the National Aeronautics and Space Administration through grant 13-EPSCoR-0012. Data were acquired at ALS beamline 9.1. The Advanced Light Source is supported by the Director, Office of Energy Research, Office of Basic Energy Sciences, Materials Sciences Division of the US Department of Energy, under Contract No. DE-AC02-05CH11231. The authors thank David Kilcoyne for his contributions to the PEPIPICO instrumentation.

Received September 11, 2013; accepted January 10, 2014.

\section{References}

1. D. Feng, J. Liu, A. P. Hitchcock, A. L. D. Kilcoyne, T. Tyliszczak, N. Riehs, E. Rühl, J. D. Bozek, D. Mcllroy, and P. A. Dowben, J. Phys. Chem. A 112 (2008) 3311.

2. E. Rühl, N. F. Riehs, S. Behera, J. Wilks, J. Liu, H.-W. Jochims, A. N. Caruso, N. Boag, J. A. Kelber, and P. A. Dowben, J. Phys. Chem. A 114 (2010) 7284.

3. E. Rühl, A. P. Hitchcock, J. D. Bozek, T. Tyliszczak, A. L. D. Kilcoyne, D. N. Mcllroy, A. KnopGericke, and P. A. Dowben, Phys. Status Solidi B 246 (2009) 1496.

4. A. N. Caruso, S. Balaz, B. Xu, P. A. Dowben, A. S. McMullen-Gunn, J. I. Brand, Y. B. Losovyj, and D. N. Mcllroy, Appl. Phys. Lett. 84 (2004) 1302.

5. A. N. Caruso, R. B. Billa, S. Balaz, J. I. Brand, and P. A. Dowben, J. Phys.-Condens. Mat. 16 (2004) L139.

6. D. L. Schulz, A. Lutfurakhmanov, B. Maya, J. Sandstrom, D. Bunzow, S. B. Qadri, R. Bao, D. B. Chrisey, and A. N. Caruso, J. Non-Cryst. Solids 354 (2008) 2369.

7. A. N. Caruso, P. A. Dowben, S. Balkir, N. Schemm, K. Osberg, R. W. Fairchild, O. B. Flores, S. Balaz, A. D. Harken, B. W. Robertson, and J. I. Brand, Mater. Sci. Eng. B 135 (2006) 129.

8. A. P. Hitchcock, A. T. Wen, S. Lee, J. A. Glass, J. T. Spencer, and P. A. Dowben, J. Phys. Chem. B 97 (1993) 8171.

9. A. P. Hitchcock, S. G. Urquhart, A. T. Wen, A. L. D. Kilcoyne, T. Tyliszczak, E. Rühl, N. Kosugi, J. D. Bozek, J. T. Spencer, D. N. Mcllroy, and P. A. Dowben, J. Phys. Chem. B 101 (1997) 3483.

10. T. Lebrun, M. Lavollée, M. Simon, and P. Morin, J. Chem. Phys. 98 (1993) 2534. 
11. M. Simon, T. Lebrun, R. Martins, G. G. B. de Souza, I. Nenner, M. Lavollée, and P. Morin, J. Phys. Chem. 97 (1993) 5228.

12. E. Rühl, C. Heinzel, H. Baumgärtel, and A. P. Hitchcock, Chem. Phys. 169 (1993) 243.

13. A. P. Hitchcock, M. J. McGlinchey, A. L. Johnson, W. K. Walter, M. Perez-Jigato, D. A. King, D. Norman, E. Rühl, C. Heinzel, and H. Baumgärtel, J. Chem. Soc. Faraday T. 89 (1993) 3331.

14. E. Rühl, C. Schmale, H. W. Jochims, E. Biller, M. Simon, and H. Baumgärtel, J. Chem. Phys. 95 (1991) 6544.

15. E. Rühl, C. Heinzel, H. Baumgärtel, M. Lavollée, and P. Morin, Z. Phys. D 31 (1994) 245.

16. E. Rühl, Int. J. Mass Spectrom. 229 (2003) 117.

17. A. P. Hitchcock and J. J. Neville, Photoionization Dynamics from Inner Shell Mass Spectrometry, Chapter 4, in: Chemical Applications of Synchrotron Radiation, Part I: Dynamics and VUV Spectroscopy, Advanced Series in Physical Chemistry, T. K. Sham (Ed.), World Scientific, Singapore 12A (2002), pp. 154-227.

18. D. M. Curtis and J. H. D. Eland, Int. J. Mass Spectrom. Ion. Proc. 63 (1985) 241.

19. A. Lindgren, M. Gisselbrecht, F. Burmeister, A. N. de Brito, A. Kivimaki, and S. L. Sorensen, J. Chem. Phys. 112 (2005) 114306.

20. T. Masukoka, J. Chem. Phys. 98 (1993) 6989.

21. G. Dujardin, D. Winkoun, and S. Leach, Phys. Rev. A 31 (1985) 3027.

22. G. Dujardin, L. Hellner, D. Winkoun, and M. Besnard, J. Chem. Phys. 105 (1986) 291.

23. J. H. D. Eland, Mol. Phys. 61 (1987) 725.

24. J. H. D. Eland, Acc. Chem. Res. 22 (1989) 281.

25. E. Rühl, S. D. Price, S. Leach, and J. H. D. Eland, Int. J. Mass Spectrom. Ion. Proc. 97 (1990) 175.

26. A. P. Hitchcock, J. J. Neville, A. Jürgensen, and R. G. Cavell, J. Electron Spectrosc. 88 (1998) 71.

27. S. Balaz, A. N. Caruso, N. P. Platt, D. I. Dimov, N. M. Boag, J. I. Brand, Ya. B. Losovyj, and P. A. Dowben, J. Phys. Chem. B 111 (2007) 7009.

28. W. C. Wiley and I. H. McLaren, Rev. Sci Instrum. 26 (1955) 1150.

29. J. K. Böhlke, J. R. de Laeter, P. De Bièvre, H. Hidaka, H. S. Peiser, K. J. R. Rosman, and P. D. P. Taylor, J. Phys. Chem. Ref. Data 34 (2005) 57.

30. B. Langer, N. Berrah, A. Farhat, O. Hemmers, and J. D. Bozek, Phys. Rev. A 53 (1996) R1946.

31. S. Bernstorff, W. Braun, M. Mast, W. Peatman, and T. Schroeter, Rev. Sci. Instrum. 60 (1989) 2097.

32. P. Lablanquie, I. Nenner, P. Millie, P. Morin, J. H. D. Eland, M. J. Hubin-Franskin, and J. Delwiche, J. Chem. Phys. 82 (1985) 2951.

33. J. H. D. Eland, in: Vaccum Ultraviolet Photoionization and Photodissociation of Molecules and Clusters, C. Y. Ng (Ed.), World Scientific, Singapore, (1991), pp. 297-343.

34. A. Lindgren, Studies of Molecular and Cluster Fragmentation Using Synchrotron Radiation: Measurements and Models, Ph. D. thesis, Lund University, Sweden, October 2006.

35. J. H. D. Eland, Acc. Chem. Res. 22 (1989) 381.

36. J. H. D. Eland, Laser Chem. 11 (1991 259.

37. B. P. Tsai and J. H. D. Eland, Int. J. Mass Spectrom. Ion Phys. 36 (1980) 143. 